\title{
Somatostatin and somatostatin analogues: pharmacokinetics and pharmacodynamic effects
}

\author{
A G Harris
}

\begin{abstract}
Somatostatin is a 14 amino acid peptide that inhibits pancreatic exocrine and endocrine secretion. Its clinical application has been limited by its very short half life, necessitating continuous intravenous infusion. Octreotide is an 8 amino acid synthetic analogue of somatostatin that possesses similar pharmacological effects. It has a much longer duration of action, however, and can be given subcutaneously. Both the intravenous and subcutaneous routes of injection of octreotide are well tolerated. Peak serum concentrations occur within 30 minutes after subcutaneous administration and within four minutes of a three minute intravenous infusion. Serum concentration increases linearly with dose. Octreotide is distributed rapidly, mainly in the plasma, where it is $65 \%$ protein bound. The elimination half life is about 1.5 hours and about $32 \%$ of a subcutaneous dose is excreted in the urine as unchanged octreotide. Octreotide inhibits gastroenteropancreatic secretion, especially of insulin, glucagon, pancreatic polypeptide, gastric inhibitory polypeptide, and gastrin. It also inhibits both release of thyroid stimulating hormone and growth hormone secretion in response to exercise, insulin induced hypoglycaemia, and argenine stimulation. Octreotide reduces splanchnic blood flow in healthy volunteers and hepatic venous pressure in cirrhotic patients. It can accelerate or delay gastric emptying, prolong transit time at moderate to high doses, stimulate motility at low doses, and inhibit gall bladder emptying. Octreotide considerably inhibits pentagastrin stimulated gastric acid secretion and significantly diminishes exocrine pancreatic function
\end{abstract}

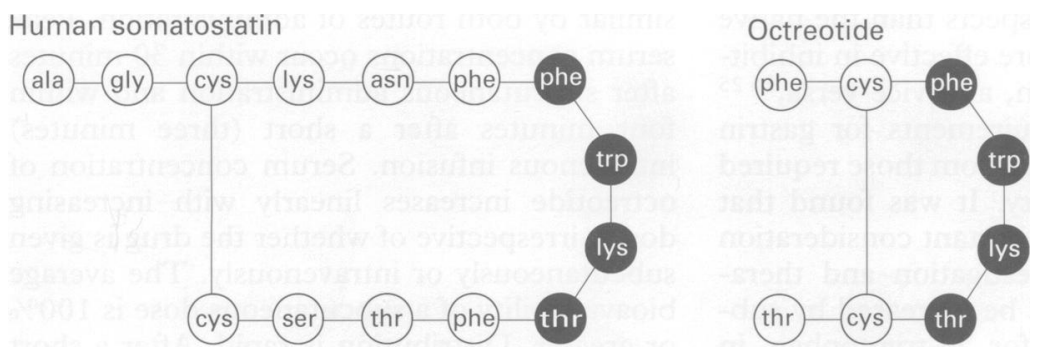

Amino acids essential

for receptor binding

Amino acid composition of somatostatin and octreotide. (amylase, trypsin, lipase). Octreotide increases intestinal transit time and decreases endogenous fluid secretion in the jejunum and ileum, thus increasing the absorption of water and electrolytes. These pharmacological effects of the analogue point to its therapeutic role in a variety of endocrine and gastrointestinal disorders.

(Gut 1994; supplement 3: S1-S4)

\section{The somatostatin family}

\section{NATIVE MOLECULAR STRUCTURES}

Somatostatin is the name given to a family of peptides, the original member of which, somatostatin 14, a tetradecapeptide, was first isolated from ovine hypothalami by Roger Guillemin's group at the Salk Institute, ${ }^{1}$ in the course of an unsuccessful search for growth hormone releasing factor. The molecule was shown to inhibit growth hormone release from cultured pituitary cells, and for a while was known variously as growth hormone release inhibiting factor, somatotropin release inhibiting factor, and growth hormone release inhibiting factor, until somatostatin - proposed by the Salk group in a note to the original article - emerged as standard.

The native molecule was found to have a cyclic structure joined by two intramolecular disulphide bonds between the two cysteine residues (Figure). The linear reduced sequence, however, proved to have the same biological activity as the cyclic form in vitro that is, the cyclic form was not essential for recognition by specific somatostatin receptors.

A second native form of somatostatin was reported in $1980 .^{2}$ Somatostatin 28 contains the amino acid sequence of somatostatin 14, extended by 14 residues at the $N$-terminus. Though there is some evidence that somatostatin 28 may act as a precursor, it also operates as a hormone in its own right, with a slightly different spectrum of activity in different tissues. Thus somatostatin 28 suppresses growth hormone for much longer, but is less effective in suppressing gastric acid. There is virtually no somatostatin 28 in the stomach and duodenum. It has been shown, however, to be the dominant form lower down the gut. ${ }^{34}$

\section{LOCALISATION}

Large amounts of somatostatin are found in the gastrointestinal system, including the pancreas, visceral autonomic nervous system, endocrine cells, and gut lumen. Immuno- 
cytochemical studies show that somatostatin is localised to the $\mathrm{D}$ cells of the pancreas and gut mucosa, particularly in the gastric fundus, antrum, and duodenum. ${ }^{56} \mathrm{D}$ cells are situated in the lower third of the crypts, from where they extend cytoplasmic processes along the basal membranes to the basal pole of neighbouring glands. ${ }^{7}$ Thus somatostatin is well placed to exercise paracrine control of other endocrine cells in the gut, for example, those responsible for the synthesis and release of gastrin. The $\mathrm{D}$ cells also have microvilli in direct contact with the lumen, thus providing a pathway by which changes in gut content can influence somatostatin production, either into the lumen or into the circulation. In addition, the gut is innervated by extrinsic and intrinsic somatostatin containing neurones, with the intrinsic neurones being present in both the submucosal and myenteric plexuses.

\section{ACTIONS}

These anatomical considerations explain how somatostatin can have multiple endocrine, paracrine, and exocrine functions, in addition to its central growth hormone release inhibiting effect. The first description of its gastrointestinal action was published within a year of the original paper. ${ }^{8}$ Somatostatin has long recognised inhibitory effects on pancreatic endocrine and exocrine secretion - that is, on insulin, glucagon, and pancreatic polypeptide $^{910}$ - and also on pancreatic enzyme and bicarbonate responses to cholecystokinin and secretin, ${ }^{11-13}$ recently reviewed by Layer et al. ${ }^{14}$ It also inhibits the secretion of a wide variety of stimulatory gastrointestinal hormones, ${ }^{15}$ and decreases gastrointestinal motility and blood flow. ${ }^{16-18}$

\section{STRUCTURE-FUNCTION RELATIONS}

The action of native somatostatin is brief and rapid, and is followed by rebound secretion, all of which suggests that it inhibits release rather than synthesis, perhaps by depressing exocytosis. ${ }^{19}$

Somatostatin receptors have been identified in the exocrine pancreas, on islet cells secreting insulin, glucagon and somatostatin, ${ }^{20}$ and on gastric cells. ${ }^{21}$ Binding of somatostatin to its receptor is accounted for primarily by the 4 amino acids in positions 7 to $10 . .^{22} 23$ In the late 1970s analogues were synthesised that were more specific in some respects than the native peptide, for example, more effective in inhibiting insulin than glucagon, and vice versa, 2425 while the structural requirements for gastrin inhibition seemed to differ from those required for action in the pituitary. It was found that duration of action, an important consideration for pharmacological investigation and therapeutic application, could be increased by substituting L-tryptophan for D-tryptophan in position 8. Preliminary results from human and animal studies with several different analogues were reported. ${ }^{26-28}$

Intracellularly, somatostatin achieves its effects by cyclic AMP dependent and independent mechanisms ${ }^{29} 30$ and may act by affecting calcium transport through the cell membrane. ${ }^{31}$ Because somatostatin inhibits many aspects of cellular function, including endocrine secretion, muscular contraction, and cellular growth, it must antagonise a variety of intracellular signalling programmes. The dephosphorylation processes crucial for secretory activity intimately participate in inhibition by somatostatin at the molecular level. After binding to its receptor, somatostatin probably acts as a dephosphorylator to inhibit secretory processes, but whether the hormone also interacts with DNA to affect transcription is disputed.

Because of its many diverse physiological effects, native somatostatin has been investigated for the treatment of acromegaly and gut endocrine tumours. Despite its many potential uses, however, the clinical applications of somatostatin were limited by a very short half life of two to three minutes, necessitating continuous intravenous infusion and resulting in rebound hypersecretion of hormones after infusion.

\section{OCTREOTIDE}

Octreotide (Sandostatin) is an 8 amino acid synthetic peptide analogue engineered to overcome the limitations of native somatostatin. ${ }^{32}$ Octreotide retains the Phe-Trp-LysThr portion of the native molecule (with the tryptophan residue in the $\mathrm{D}$ configuration), which is believed to constitute the essential pharmacophore ${ }^{22} 23$ and to be critical for gut specificity. ${ }^{33}$ Octreotide has greater pharmacological activity than the native molecule (being at least 20 times more potent in suppressing growth hormone secretion in vivo), is more selective for the inhibition of growth hormone than of insulin, and has a much enhanced duration of action (an elimination half life of 113 minutes compared with the two to three minutes of somatostatin). ${ }^{32}$ The synthetic molecule is sufficiently stable even to retain some activity on oral administration, the oral dose required to inhibit growth hormone secretion by $50 \%$ being $125 \mu \mathrm{g} / \mathrm{kg}$ after one hour. ${ }^{34}$

As octreotide is incompletely absorbed after oral administration, investigation of its pharmacokinetic profile used intravenous and subcutaneous injection. Both routes of injection are well tolerated and the incidence of side effects is low. Moreover, bioavailability is similar by both routes of administration. Peak serum concentrations occur within 30 minutes after subcutaneous administration and within four minutes after a short (three minutes) intravenous infusion. Serum concentration of octreotide increases linearly with increasing doses, irrespective of whether the drug is given subcutaneously or intravenously. The average bioavailability of a subcutaneous dose is $100 \%$ or greater. Distribution is rapid. After a short (three minutes) intravenous infusion, a very rapid distribution phase $\left(\mathrm{t}_{1 / 2 \mathrm{~b}} 0 \cdot 142-0 \cdot 210 \mathrm{~h}\right)$ is seen. Once in the blood, octreotide is distributed mainly in the plasma where it is $65 \%$ protein bound - mostly to lipoproteins, and to 
a lesser degree to albumin. The elimination half life $\left(t_{1 / 2 b}\right)$ of octreotide by either route of administration is approximately 1.5 hours -30 times longer than that of somatostatin. About $32 \%$ of a subcutaneous dose is excreted in the urine as unchanged octreotide.

In patients with severe renal impairment, the plasma clearance of octreotide is reduced by $50 \% .{ }^{35}$ This significant reduction points to the presence of a renal component in the elimination of the drug. Thus, when treating patients with renal impairment, the dose of octreotide should be carefully titrated.

Other notable findings reported in the original paper ${ }^{32}$ were that despite being much more potent than the native molecule, octreotide was better tolerated by laboratory animals, while preliminary trials in humans failed to identify any adverse effects up to the highest infused dose of $50 \mu \mathrm{g} /$ hour (many times higher than the minimal effective dose for inhibiting arginine stimulated growth hormone release). The safety of octreotide was subsequently confirmed in a wide variety of clinical situations, particularly in two unexpected respects: firstly, most studies reporting the use of octreotide in infants have shown no inhibition of growth, ${ }^{36-41}$ while secondly, in contrast with the native molecule, rebound endocrine hypersecretion does not occur when octreotide is withdrawn. ${ }^{42}$

Octreotide inhibits normal growth hormone secretion in response to exercise, insulin induced hypoglycaemia, and arginine stimulation. Studies have shown that octreotide inhibits the release of thyroid stimulating hormone by thyrotropin releasing hormone in healthy subjects. In both studies, the response of prolactin to thyrotropin releasing hormone was not affected. Moreover, basal thyroid stimulating hormone concentration was unaffected in the absence of a thyrotropin releasing hormone challenge. Octreotide blunts the luteinising hormone response to luteinising hormone releasing hormone, but has no effect on the response of follicle stimulating hormone. Adrenocorticotrophic hormone and cortisol concentrations do not change.

Octreotide exerts a number of pharmacological effects on the gastrointestinal tract. It considerably increases intestinal transit time and endogenous fluid secretion in the jejunum and ileum. As a result, absorption of water and electrolytes is increased.

Delay of intestinal transit time was shown in normal subjects undergoing steady state perfusion studies of the small bowel. Mean transit time through a $30 \mathrm{~cm}$ segment of jejunum was found to be increased from $4 \cdot 0$ to $17 \cdot 0$ minutes. Additionally, a significant decrease in endogenous flow from above the test segment was noted during the treatment period..$^{33}$

Octreotide appreciably suppresses gastroenteropancreatic secretion, especially that of insulin, glucagon, pancreatic polypeptide, gastric inhibitory polypeptide, and gastrin. This action has been seen both before and after meals, but is less pronounced three hours after a meal, when physiological release of the peptides had already been completed.
Postprandial hyperglycaemia and an increase in fasting plasma glucose have been noted, both probably associated with the decrease in insulin secretion.

Effective suppression of plasma concentrations of insulin and glucagon has been achieved with subcutaneous administration of doses as low as $5 \mu \mathrm{g}$ given 30 minutes before a test meal. Studies have shown that octreotide induces postprandial hyperglycaemia in normal subjects. ${ }^{44}$ Patients with non-insulin dependent diabetes mellitus, however, do not experience deterioration in glucose tolerance. ${ }^{44}$

Octreotide seems to be a strong inhibitor ( $80 \%$ decrease in healthy subjects) of secretin/ cholecystokinin induced pancreatic enzyme secretion (amylase, trypsin, lipase) and gall bladder contraction. ${ }^{46}$ This inhibitory effect, however, decreases with time.

Octreotide has been shown to reduce splanchnic blood flow in healthy volunteers and hepatic venous pressure in cirrhotic patients. It has also been shown to accelerate or delay gastric emptying, prolong transit time at moderate to high doses, stimulate motility at low doses, and inhibit gall bladder emptying. Octreotide considerably increases intestinal transit time and endogenous fluid secretion in the jejunum and ileum. As a result, absorption of water and electrolytes is increased.

Octreotide considerably inhibits pentagastrin stimulated gastric acid secretion ${ }^{47}$ and significantly diminishes exocrine pancreatic function (amylase, trypsin, lipase).

Because of these diverse pharmacological effects, octreotide has been studied in a wide variety of endocrine and gastrointestinal disorders (fistulae, variceal bleeding, diarrhoea, pancreatitis).

1 Brazeau P, Vale W, Burgus R, et al. Hypothalamic polypeptide that inhibits the secretion of immunoreactive pituitary growth hormone. Science 1973; 178: 77-9.

2 Praydayrol L, Jomvall H, Mutt V, Ribet A. N-terminally extended somatostatin: the primary structure of somatostatin-28. FEBS Lett 1980; 109: 55-8.

3 Descos F, de Parscau L, Olive C, Chayvialle JA. Somatostatin-like immunoreactivity in human gastrointestinal mucosa [Abstract]. 2nd International Symposium on Somatostatin, Athens, 1-3 June 1981

4 Penman E, Wass JAH, Butler MG, et al. Distribution and characterisation of immunoreactive somatostatin in human gastrointestinal tract. Regul Pept 1983; 7: 53-65.

5 Polak JM, Pearse AGE, Grimelius L, et al. Growth hormone release inhibiting hormone in gastrointestinal and pancreatic D cells. Lancet 1975; i: 1220-2.

6 Dubois MP. Immunoreactive somatostatin is present in discrete cells of the endocrine pancreas. Proc Natl Acad Sci USA 1975; 72: 1340-3.

7 Larsson LI, Goltermann N, De Magistris L, et al. Somatostatin cell processes as pathway for paracrine secretion. Science 1979; 205: 1393-5.

8 Bloom SR, Mortimer CH, Thomer MG, et al. Inhibition of gastrin and gastric acid secretion by growth hormone release-inhibiting hormone. Lancet 1974; ii: 1106-9.

9 Adrian TE, Bloom SR, Besterman HS, Bryant MG. PP-physiology and pathology. In: Bloom SR, ed. Gut

10 Floyd JC, Fajans SS, Pek S. Physiological regulation of plasma levels of PP in man. In: Bloom SR, ed. Gut plasma levels of PP in man. In: Bloom SR, ed. Gut
hormones. New York: Churchill Livingstone, 1978: hormones.

11 Boden G, Sivitz MC, Owen OE, et al. Somatostatin suppresses secretin and pancreatic exocrine secretion. Science 1975; 190: 163-4.

12 Dollinger HC, Raptis S, Pfeiffer EF. Effects of somatostatin on exocrine and endocrine pancreatic function stimulated by intestinal hormones in man. Horm Metab Res 1976; 8: 74-8.

13 Konturek SJ, Tasler J, Obtulowicz W, et al. Effect of growth hormone release inhibiting tissue on hormones stimulating exocrine pancreatic secretion. $\mathcal{F}$ Clin Invest $1976 ; 58: 1-6$.

14 Layer $P$, vd Ohe M, Muller MK, Beglinger C. Effects of somatostatin on the exocrine pancreas. Scand $f$ Gastroenterol 1991; 26: 129-36. 
15 Arnold R, Linkisch BG. Somatostatin and the gastrointestinal tract. Clin Gastroenterol 1980; 9: 733-53.

16 Bloom SR, Ralphs DN, Besser GM, et al. Effect of somatostatin on motilin levels and gastric emptying [Abstract] Gut 1975; 16: 834 .

17 Wahren J, Felig P. Influence of somatostatin on carbohydrate disposal and absorption in diabetes mellitus. Lancet 1976; ii: 1213-5.

18 Konturek SJ, Krol R, Pawlik W, et al. Pharmacology of somatostatin. In: Bloom SR, ed. Gut hormones. New York: Churchill Livingstone, 1978: 457-62.

19 Kraicer J, Spence JW. Release of growth hormone from purified somatotrophs: use of high $\mathrm{K}^{+}$and the ionophore A23187 to elucidate interrelations among $\mathrm{Ca}^{++}$, adenosine 3',5'monophosphate and somatostatin. Endocrinology 1981; 108: 651-7.

20 Mehler PS, Sussman AL, Maman A, et al. Role of insulin secretagogos in the regulations of somatostatin binding by isolated rat islets. $\mathcal{F}$ Clin Invest 1980; 66: 1334-8.

21 Reyl F, Silve C, Lewin MJM. Somatostatin receptors on isolated gastric cells. In: Rosselen $G$, Fromageot $P$, Bonfils $S$, eds. Hormone receptors in digestion and nutrition. Amsterdam: Elsevier, 1979: 391-400.

22 Veber DF, Holly FW, Nutt RF, et al. Highly active cyclic and bicyclic somatostatin analogues of reduced ring size. Nature 1979; 280: 512-4.

23 Veber DF, Freidinger RM, Schwenk-Perlow D, et al. A potent cyclic hexapeptide analogue of somatostatin. potent cyclic hexapeptide

24 Brown M, Vale W, Rivier J. Insulin selective somatostatin (SS) analogs. Diabetes 1977; 26 (suppl 1): 29

25 Brown M, Rivier J, Vale W. Somatostatin-28: selective action on the pancreatic B cell and brain. Endocrinology 1981; 108: 2391-3.

26 Vale W, Rivier J, Ling N, Brown M. Somatostatin analogs. Metabolism 1978; 27 (suppl): 1391-401.

27 Cai RZ, Szoke B, Lu R, et al. Synthesis and biological activity of highly potent octapeptide analogs of somatostatin. Proc Natl Acad Sci USA 1986; 83: 1896-900.

28 Gottesman I, Tobert J, Vandlen R, Gerich J. Efficacy, pharmacokinetics and tolerability of a somatostatin pharmacokinetics and tolerability of a somatostatin mellitus. Life Sci 1986; 38: 2211-9.

29 Bausher LP, Horio B. Neuropeptide Y and somatostatin inhibit stimulated cyclic AMP production in rabbit ciliary processes. Curr Eye Res 1990; 9: 371-8.

$30 \mathrm{McNellis} \mathrm{EL}$, Bausher LP. Stimulatory and inhibitory cyclic AMP responses in rabbit ciliary processes after cervical ganglionectomy. Curr Eye Res 1991; 10: 399-407.

31 Luft R, Efendic S, Hokfelt T. Somatostatin: both hormone and neurotransmitter? Diabetologia 1978; 14: 1-13.

32 Bauer W, Briner U, Doepfner W, et al. Octreotide: a very potent and selective octapeptide analogue of somatostatin with prolonged action. Life Sci 1982; 31: 1133-40.

33 Rosenthal LE, Yamashiro DJ, Rivier J, et al. Structureactivity relationship of somatostatin analogs in the rabbit ileum and the rat colon. $\mathcal{f}$ Clin Invest 1983; 71: 840-9.
34 Williams G, Burrin JM, Ball JA, Joplin GF, Bloom SR. Effective and lasting growth-hormone suppression in active acromegaly with oral administration of somatostatin analogue SMS 201-995. Lancet 1986; ii: 774-8.

35 Kallivretakis N, Yetis A, Del Pozo E, et al. Pharmacokinetics of SMS 201-995 in normal subjects and in patients with severe renal failure. Neuroendocrinol Lett 1985; 7: 92 .

36 Jackson JA, Hahn HB Jr, Oltorf CE, O'Dorisio TM, Vinik AI. Long term treatment of refractory neonatal hypoglycemia with long acting somatostatin analogue. $₹$ Pediatr 1987; 111: 548-51.

37 Ohlbaum P, Galperine RI, Demarquez IL, et al. Use of a long acting somatostatin analogue (octreotide) in controlling a significant ileal output in a 5 year-old child. $\mathcal{F}$ Pediat Gastroenterol Nutr 1987; 6: 466-70.

38 Jaros W, Biller J, Greer S, O'Dorisio T, Grand R. Successful treatment of idiopathic secretory diarrhoea of infancy with the somatostatin analogue SMS 201-995. Gastroenterology 1988; 94: 189-93.

39 Wilson DC, Carson DJ, Quinn RJM. Long term use of somatostatin analogue octreotide in the treatment of hypoglycemia due to nesidioblastosis. Acta Paediatr Scand 1988; 77: 467-70.

40 Lamireau T, Galperine RI, Ohlbaum P, et al. Use of a long acting somatostatin analogue in controlling ileostomy diarrhoea in infants. Acta Paediatr Scand 1990; 79: diarrho $871-2$.

41 Hawdon JM, Ward Platt MP, Lamb VM, Aynsley-Green A Tolerance to somatostatin analogue in a preterm infant with islet cell dysregulation syndrome. Arch Dis Child 1990; 65: 341-3.

42 Lamberts SWJ, Oosterom R, Neufeld M, del Pozo E. The somatostatin analog octreotide induces long-acting inhibition of growth hormone secretion without rebound hypersecretion in acromegalic patients. $\mathcal{f}$ Clin Endocrinol Metab 1985; 60: 1161-5.

43 Dueno MI, Pai JC, Santangelo WC, Krejs GJ. Effect of somatostatin analog on water and electrolyte transport and transit time in human small bowel. Dig Dis Sci 1987; 32: 1092-6.

44 Johnston DG, Davies RR, Turner SJ. Effects of somatostatin and SMS 201-995 on carbohydrate metabolism in normal man. Scand $\mathcal{f}$ Gastroenterol 1986; 21 (suppl 119): 158-65.

45 Williams G, Fuessl H, Kraenzlin M, et al. Postprandial effects of SMS 201-995 on gut hormones and glucose tolerance. Scand $\mathcal{F}$ Gastroenterol 1986; 21 (suppl 119): 73-83.

46 Lembcke B, Creutzfeldt W, Schlesser S, et al. Effect of somatostatin analogue sandostatin (SMS 201-995) on hormone release in normal men. Digestion 1987; 36: 108-24.

47 Gyr KE, Whitehouse I, Beglinger C, et al. Human pharmacological effects of SMS 201-995 on gastric secretion. Scand $\mathcal{F}$ Gastroenterol 1986; 21 (suppl 119): 96-102. 